\title{
Current Venous Thromboembolism Prevention Practices Following Endovascular Electrophysiological Procedures in the UK A retrospective study
}

"Christopher Saunderson, ${ }^{1}$ Sally Hickman, ${ }^{1}$ Elaine Wilkinson, ${ }^{2}$ Muzahir Tayebjee ${ }^{1}$

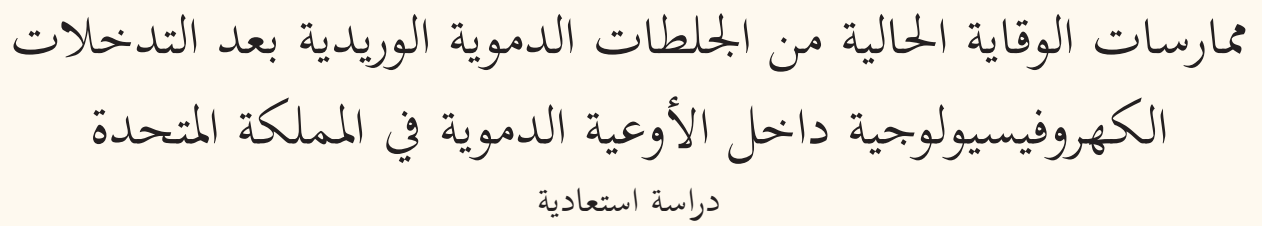

كريستوفر ساوندرسون، سالي هيكمان، الين ويلكينسون، مظفر الطيبجي

ABSTRACT: Objectives: This study aimed to evaluate the incidence of venous thromboembolism (VTE) cases at the Leeds General Infirmary, Leeds, UK, as well as to survey current VTE practices and preventative strategies at other UK-based electrophysiology (EP) centres. Methods: This retrospective study involved all patients who underwent EP studies at Leeds General Infirmary from January 2014 to December 2016. In addition, a telephone survey was conducted of 35 other UK-based EP centres. Results: Of 1,020 patients who underwent EP studies at Leeds General Infirmary, 0.3\% developed a post-procedural VTE. In addition, 28 other EP centres were surveyed (response rate: $80 \%$ ), of which $18 \%$ reported VTE cases in the last two years. There were wide variations in VTE prevention strategies and the use of post-procedural thromboprophylaxis. Conclusion: Despite the low incidence of VTE cases, many UK centres continue to experience this complication with no consensus on optimal preventative strategies. As current VTE guidelines do not recommend antithrombotics after EP studies, further research is needed.

Keywords: Venous Thromboembolism; Cardiac Electrophysiological Techniques; Catheter Ablation; Heparin; Postoperative Complications; Risk Assessment; United Kingdom.

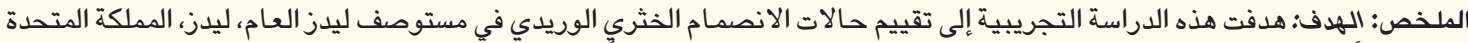

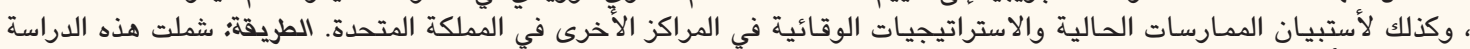

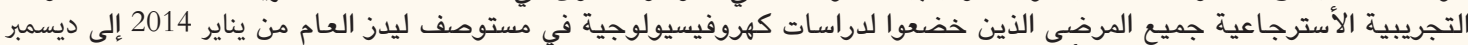

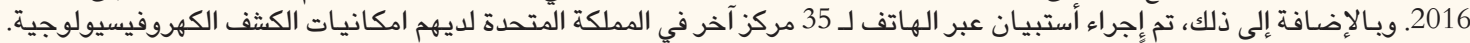

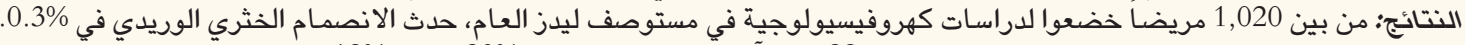



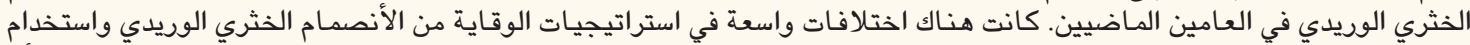

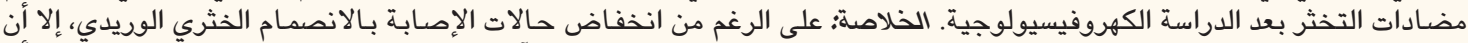

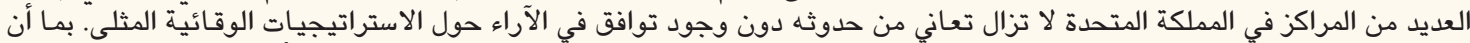

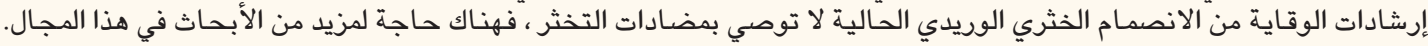

الكامـات المفتاحية: الانصمام الخثري الوريدي؛ تقنيات القلب الكهروفيسيولوجية؛ الاستئصال باستخدام القسطرة؛ الهيبارين؛ مضاعفات ما بعد الجراحة؛ تقييم المخاطر؛ المملكة المتحدة.

$\mathrm{E}$ LECTROPHYSIOLOGY (EP) STUDIES AND RADIOfrequency ablation (RFA) require the introduction of multiple catheters into the venous system. ${ }^{1,2}$ A typical procedure involves the placement of 4-5 sheaths into the femoral veins through which EP catheters are passed into the heart. If necessary, access to the left-sided cardiac chambers is achieved via a trans-septal puncture or by accessing the left ventricle with a retrograde approach via the femoral artery. However, the period of immobility during and after the procedure-typically up to six hours-is a known thrombotic risk factor. The incidence of asymptomatic deep vein thrombosis (DVT) in this setting ranges from $5-18 \%$, although the clinical incidence is substantially lower $(0.4-2 \%) .^{1-4}$

Venous thromboembolism (VTE) has potentially serious clinical and financial consequences; according to the National Institute for Health and Care Excellence (NICE), an estimated 25,000 patients die every year from preventable VTE in the UK. ${ }^{5-8}$ The NICE guidelines recommend that clinicians assess and stratify all individuals admitted to hospital in order to administer pro- 
phylactic anticoagulants to those at risk of VTE. ${ }^{5}$ The European Heart Rhythm Association (EHRA) guidelines on the use of antithrombotics in EP procedures suggest the peri-procedural administration of therapeutic unfractionated heparin (UFH) to achieve an activated clotting time (ACT) of $\geq 300$ seconds for left-sided procedures and consideration of its use in right-sided procedures. ${ }^{9}$ However, they do not specifically recommend the use of oral anticoagulants or antiplatelets following EP procedures, except in cases of atrial fibrillation, flutter ablation or left-sided ventricular tachycardia ablation. ${ }^{9}$

This study aimed to establish the incidence of post-procedural VTE among patients undergoing EP studies with or without RFA, excluding those taking therapeutic anticoagulants, at the Leeds General Infirmary, Leeds, UK. In addition, other UK-based centres were surveyed to document whether they had experienced VTE in the last two years and current practices for VTE prevention.

\section{Methods}

This retrospective study took place at the Leeds General Infirmary between January 2014 and December 2016. A review of the EP procedures database was performed to identify all patients with a documented complication of DVT or a pulmonary embolism. The patients' medical records were then checked to ensure that appropriate testing had been performed to confirm the diagnosis of VTE, such as ultrasound venography or computed tomography pulmonary angiography. The case notes of patients with confirmed VTE were then reviewed in terms of medical history, EP procedure and the administration of peri- and post-procedural antithrombotics. All patients who required pre- or postprocedural therapeutic anticoagulation measures-such as those with atrial fibrillation or flutter-were excluded from the study.

Subsequently, a telephone survey was conducted of EP consultants or registrars working at 35 National Health Service (NHS) Trust centres performing >100 ablation procedures per year. ${ }^{10}$ The survey recorded whether the centres had experienced any cases of VTE complications in the last two years. Verbal instructions were given prior to the survey to ensure that patients requiring therapeutic anticoagulation were not included. In addition, data were collected on the centres' current practices regarding the use of peri- and postprocedural antithrombotics in both right-sided and left-sided EP procedures.

This study was approved as a service evaluation project by the Research \& Innovation Department of the Leeds Teaching Hospital NHS Trust. All telephone
Table 1: Sociodemographic, clinical and procedural characteristics of post-procedural venous thrombosis cases at the Leeds General Infirmary, Leeds, UK $(\mathrm{N}=3)$

\begin{tabular}{|c|c|c|c|}
\hline Characteristic & Case 1 & Case 2 & Case 3 \\
\hline \multicolumn{4}{|l|}{ Sociodemographic } \\
\hline Gender & Female & Female & Male \\
\hline Age in years & 64 & 68 & 81 \\
\hline \multicolumn{4}{|l|}{ Clinical } \\
\hline $\begin{array}{l}\text { Presence of cardiac } \\
\text { or respiratory } \\
\text { comorbidities }\end{array}$ & None & None & IHD and COPD \\
\hline $\begin{array}{l}\text { Active cancer or } \\
\text { cancer treatment }\end{array}$ & No & No & No \\
\hline $\begin{array}{l}\text { Previous history of } \\
\text { VTE }\end{array}$ & No & No & No \\
\hline $\begin{array}{l}\text { Oestrogen- } \\
\text { containing therapy }\end{array}$ & Yes & No & No \\
\hline $\begin{array}{l}\text { Recent major } \\
\text { surgery }\end{array}$ & No & No & No \\
\hline $\mathrm{BMI}$ in $\mathrm{kg} / \mathrm{m}^{2}$ & 41 & 34 & 24 \\
\hline \multicolumn{4}{|l|}{ Procedural } \\
\hline Type of procedure & $\begin{array}{l}\text { EP study } \\
\text { and } \\
\text { RFA for } \\
\text { AVNRT }\end{array}$ & $\begin{array}{l}\text { EP } \\
\text { study }\end{array}$ & $\begin{array}{l}\text { EP study and } \\
\text { attempted VT } \\
\text { ablation }\end{array}$ \\
\hline Duration in minutes & 150 & 30 & 135 \\
\hline Access site & RFV & RFV & $\begin{array}{c}\text { RFV and } \\
\text { artery with } \\
\text { a retroaortic } \\
\text { approach to the } \\
\text { LV }\end{array}$ \\
\hline Sheath sizes & $\begin{array}{l}2 \times 5 \mathrm{~F} \\
2 \times 7 \mathrm{~F}\end{array}$ & $\begin{array}{l}2 \times 5 \mathrm{~F} \\
2 \times 7 \mathrm{~F}\end{array}$ & $\begin{array}{l}1 \times 4 \mathrm{~F} \\
3 \times 7 \mathrm{~F} \\
1 \times 8 \mathrm{~F}\end{array}$ \\
\hline $\begin{array}{l}\text { Number of } \\
\text { catheters used }\end{array}$ & 4 & 4 & 5 \\
\hline $\begin{array}{l}\text { Peri-procedural } \\
\text { heparin } \\
\text { administered in } U\end{array}$ & 3,000 & 2,000 & $9,000^{*}$ \\
\hline $\begin{array}{l}\text { Previous history of } \\
\text { EP procedures in } \\
\text { the past year }\end{array}$ & Yes & No & Yes \\
\hline $\begin{array}{l}\text { Time from } \\
\text { procedure to VTE } \\
\text { diagnosis in days }\end{array}$ & 24 & 11 & 76 \\
\hline $\begin{array}{l}\text { Pre-procedure } \\
\text { antiplatelet therapy } \\
\text { prescribed }\end{array}$ & No & No & $\begin{array}{c}75 \text { mg of aspirin } \\
\text { daily }\end{array}$ \\
\hline $\begin{array}{l}\text { Post-procedure } \\
\text { antiplatelet therapy/ } \\
\text { anticoagulants } \\
\text { prescribed upon } \\
\text { discharge }\end{array}$ & No & No & $\begin{array}{c}75 \text { mg of aspirin } \\
\text { daily }\end{array}$ \\
\hline
\end{tabular}

$I H D=$ ischaemic heart disease COPD = chronic obstructive pulmonary disease; $V T E=$ venous thromboembolism; $B M I=$ body mass index; $E P=$ electrophysiological; $R F A=$ radiofrequency ablation; $A V N R T=$ atrioventricular nodal re-entry tachycardia; $V T=$ ventricular tachycardia $; F V=$ right femoral vein; $L V=$ left ventricle. "Prior to the activated clotting time being maintained at $>300$ seconds. 


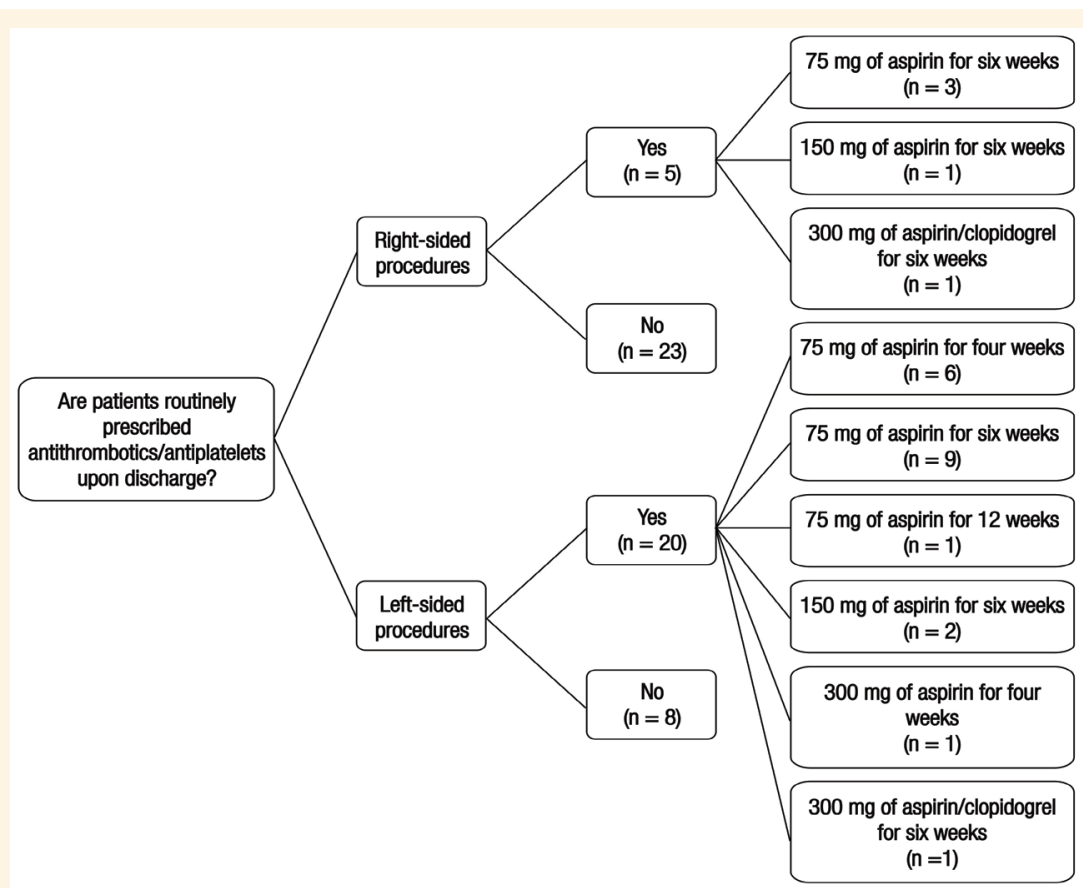

Figure 1: Flow chart showing the proportion of patients receiving antithrombotics/antiplatelets upon discharge and specific regimens according to UK-based electrophysiology centres $(\mathrm{N}=28)$.

survey participants gave informed verbal consent prior to participation in the study.

\section{Results}

Out of 1,020 adult patients undergoing EP procedures at the Leeds General Infirmary during the study period, three patients $(0.3 \%)$ had post-procedural pulmonary emboli. In addition, the third case had confirmed rightsided common femoral DVT. Two of the patients underwent right-sided procedures, while one patient underwent a left-sided procedure for attempted ventricular tachycardia ablation. The procedure times ranged from 30-150 minutes. Two patients had high body mass indices. Case one was receiving oestrogen-containing therapy and case three had ischaemic heart disease along with chronic obstructive pulmonary disease. Two patients received a nominal dose of UFH at the start of the procedure, while the third received full therapeutic anticoagulation; however, none of the patients received postprocedural anticoagulation therapy. One patient took a daily dose of $75 \mathrm{mg}$ of aspirin prior to the procedure, which was continued upon discharge [Table 1]. Following the VTE diagnosis, all patients diagnosed with pulmonary emboli received at least three months of oral therapeutic anticoagulants as recommended by current guidelines, with no further complications observed. ${ }^{11}$

Of the 35 UK-based centres performing $>100$ ablation procedures per year, 28 centres participated in the survey (response rate: $80 \%$ ). The majority (68\%) had a formal process for reviewing EP complications.
A quarter of the centres perceived VTE to be a serious complication following EP procedures, with 18\% reporting cases of VTE complications occurring in the last two years. All of the centres confirmed that they administered therapeutic UFH (for an ACT of $\geq 300$ seconds) during left-sided procedures. In contrast, only $7 \%$ used a nominal dose of UFH (3,000-5,000 U) during rightsided procedures. The majority of centres (61\%) mobilised patients an average of 2-3 hours after their procedure, with other centres mobilising patients at $1-2$ hours (11\%), 3-4 hours (25\%) or $>4$ hours (3\%). Most centres reported prescribing antiplatelet medications upon discharge to patients undergoing left-sided procedures, with very few centres prescribing these to patients undergoing rightsided procedures ( $71 \%$ versus $18 \%$, respectively). If antiplatelet medications were prescribed, the centres reported prescribing either aspirin or clopidogrel (dose range: 75-300 mg) for a duration of 4-12 weeks [Figure 1]. None of the centres reported prescribing anticoagulants upon discharge.

\section{Discussion}

At Leeds General Infirmary, 0.3\% of patients undergoing EP procedures-excluding those on therapeutic anticoagulants-were diagnosed with a VTE within 6-12 weeks of the procedure. These findings are in accordance with those in the published literature. ${ }^{1-4}$ In addition, all three of the affected patients had additional VTE risk factors. Crucially, the survey identified a wide variation in VTE prevention strategies at UK-based EP centres, 
particularly with regards to UFH use during right-sided EP procedures and the prescription of antithrombotic medications upon discharge.

Peri-procedural UFH in left-sided EP procedures is a well-established therapy to reduce thromboembolic complications, particularly in atrial fibrillation, and is recommended in multiple guidelines. ${ }^{9,12}$ In the current study, all of the surveyed centres reported using periprocedural UFH during left-sided procedures. In contrast, the role of peri-procedural UFH in rightsided procedures is unclear. Alizadeh et al. conducted a randomised clinical trial (RCT) in which 200 patients with right-sided supraventricular and ventricular tachyarrhythmias undergoing EP studies with and without RFA were randomised to two groups; the first group was administered intra-procedural heparin (a 5,000-U bolus with subsequent $\mathrm{ACT}$ measurement), while the second received no anticoagulation measures. ${ }^{13}$ After 24 hours, duplex ultrasonography revealed no cases of symptomatic DVT in either group. However, there was a significant decrease in the rate of $i n$ situ thrombosis between the heparin and control groups ( $11 \%$ versus $28 \% ; P=0.04) .{ }^{13}$

In another RCT, 27 patients undergoing EP studies were randomised to receive either a fixed dose of 5,000 U of low-molecular-weight heparin (LMWH) one hour before the procedure or no anticoagulation measures. ${ }^{14}$ Duplex ultrasonography performed 24 hours, one week and one month after sheath removal demonstrated a significant reduction in asymptomatic venous thrombi cases in the LWMH group compared to the control group (18.1\% versus $62.5 \%$; $P=0.02$ ). However, the trial had a very small sample size with no clinical incidences of DVT. ${ }^{14}$ Such studies provide a possible explanation for the low utilisation of peri-procedural anticoagulation therapy in right-sided procedures across the UK. ${ }^{13,14}$ In the current study, nominal doses of heparin did not prevent VTE complications occurring in two patients undergoing right-sided procedures.

Antiplatelet therapy is not indicated for VTE prophylaxis. ${ }^{5}$ Furthermore, the EHRA guidelines do not routinely recommend the use of oral anticoagulants or post-procedural antiplatelet therapy for EP procedures, except for patients with atrial fibrillation, atrial flutter or left ventricular tachycardia. ${ }^{9}$ However, current clinical practices do not appear to reflect this; according to findings from the telephone survey, $71 \%$ of centres prescribed antiplatelet therapy after leftsided procedures and $18 \%$ after right-sided procedures. A recent RCT of 176 patients who had undergone RFA-excluding atrial fibrillation ablation-compared the use of direct oral anticoagulants (10 mg of rivaroxaban once a day) with aspirin (100 mg once a day) for three months after EP procedures. ${ }^{15}$ Duplex ultrasonography was performed 48-72 hours after the proc- edure, with no complete occlusive thrombus events. However, rivaroxaban significantly decreased the incidence of nonocclusive thrombi compared to aspirin (5.8\% versus $16.7 \% ; P=0.023) .{ }^{15}$ The low event rate of symptomatic VTE in this population indicates that there is no consistent benefit of peri- or post-procedural antithrombotic therapy in VTE prevention. Therefore, further studies with larger samples are needed to substantiate recommendations for VTE prophylaxis after EP procedures.

This retrospective study was subject to several limitations. Although patients were seen at least once after their procedure at the Leeds General Infirmary, some patients underwent longer-term follow-up at other district hospitals; thus, some VTE events may not have been reported. Additionally, patients with identified VTE complications also had other thrombotic risk factors, the influence of which was not evaluated in the present study. Furthermore, a small proportion of centres did not respond to the telephone questionnaire. Finally, the survey results were based on self-reported data from a single individual and thus may not be an accurate reflection of the wider experience or actual practices at the institutions.

\section{Conclusion}

In this study, the post-procedural rate of VTE complications was $0.3 \%$ among patients undergoing EP studies with or without RFA at Leeds General Infirmary, excluding those who underwent atrial fibrillation ablation or who were taking oral anticoagulants. Unfortunately, $18 \%$ of surveyed UK-based centres also reported having experienced this complication within the preceding two years, with current practices for the prevention of VTE differing between centres. Prophylactic measures for VTE prevention are hampered by a lack of data to aid decision-making. Therefore, larger-scale studies are required to adequately assess the risks and benefits of peri- and post-procedural thromboprophylaxis.

\section{ACKNOWLEDGEMENTS}

A poster of the preliminary version of this study was presented at the Heart Rhythm Congress 2017 on 1-4 October 2017 in Birmingham, UK. An abstract of this poster presentation was subsequently published in Europace in October 2017, Volume 19, Issue S1, P. i49.

\section{CONFLICT OF INTEREST}

Dr Muzahir Tayebjee received research and travel grants from Biosense Webster Inc. (Irvine, California, USA), St. Jude Medical Inc. (Saint Paul, Minnesota, USA), Medtronic PLC (Dublin, Ireland) and Boehringer Ingelheim GmbH (Ingelheim am Rhein, Germany). The other authors declare no conflicts of interest. 


\section{FUNDING}

No funding was received for this study.

\section{References}

1. Moubarak G, Bonhomme S, Vedrenne G, Bouleti C, Ollitrault J, Priollet P, et al. Femoral vein thrombosis after right-sided electrophysiological procedures. J Interv Card Electrophysiol 2013; 38:155-8. doi: 10.1007/s10840-013-9832-4.

2. Chen JY, Chang KC, Lin YC, Chou HT, Hung JS. Safety and outcomes of short-term multiple femoral venous sheath placement in cardiac electrophysiological study and radiofrequency catheter ablation. Jpn Heart J 2004; 45:257-64. doi: 10.1536/ jhj.45.257.

3. Michelucci A, Antonucci E, Conti AA, Alessandrello Liotta A, Fedi S, Padeletti L, et al. Electrophysiologic procedures and activation of the hemostatic system. Am Heart J 1999; 138:128-32. doi: 10.1016/s0002-8703(99)70257-7.

4. Hindricks G. The Multicentre European Radiofrequency Survey (MERFS): Complications of radiofrequency catheter ablation of arrhythmias. Eur Heart J 1993; 14:1644-53. doi: 10.1093/eurhe $\operatorname{artj} / 14.12 .1644$.

5. National Institute of Health and Care Excellence. Venous thromboembolism in over 16s: Reducing the risk of hospital-acquired deep vein thrombosis or pulmonary embolism. From: www. nice.org.uk/guidance/ng89 Accessed: Mar 2018.

6. Li YC, Lin J, Wu L, Li J, Chen P, Guang XQ. Clinical features of acute massive pulmonary embolism complicated by radiofrequency ablation: An observational study. Medicine (Baltimore) 2015; 94:e1711. doi: 10.1097/MD.0000000000001711.

7. Fanikos J, Rao A, Seger AC, Carter D, Piazza G, Goldhaber SZ. Hospital costs of acute pulmonary embolism. Am J Med 2013; 126:127-32. doi: 10.1016/j.amjmed.2012.07.025.
8. National Institute of Health and Care Excellence. Venous thromboembolism: Reducing the risk for patients in hospital. From: www.nice.org.uk/guidance/cg92 Accessed: Mar 2018.

9. Sticherling C, Marin F, Birnie D, Boriani G, Calkins H, Dan GA, et al. Antithrombotic management in patients undergoing electrophysiological procedures: A European Heart Rhythm Association (EHRA) position document endorsed by the ESC Working Group Thrombosis, Heart Rhythm Society (HRS), and Asia Pacific Heart Rhythm Society (APHRS). Europace 2015; 17:1197-214. doi: 10.1093/europace/euv190.

10. British Heart Rhythm Society. National audit of cardiac ablation: 2013-14. From: www.bhrs.com/files/files/Audit\%20Reports/A blation\%20Report\%202013-14\%20version\%209\%20Final(1).pdf Accessed: Mar 2018

11. Konstantinides SV, Torbicki A, Agnelli G, Danchin N, Fitzmaurice D, Galiè N, et al. 2014 ESC Guidelines on the diagnosis and management of acute pulmonary embolism. Eur Heart J 2014; 35:3033-69. doi: 10.1093/eurheartj/ehu283.

12. Wazni OM, Rossillo A, Marrouche NF, Saad EB, Martin DO, Bhargava M, et al. Embolic events and char formation during pulmonary vein isolation in patients with atrial fibrillation: Impact of different anticoagulation regimens and importance of intracardiac echo imaging. J Cardiovasc Electrophysiol 2005; 16:576-81. doi: 10.1111/j.1540-8167.2005.40480.x.

13. Alizadeh A, Yazdi AH, Kafi M, Rad MA, Moradi M, Emkanjoo Z. Predictors of local venous complications resulting from electrophysiological procedures. Cardiol J 2012; 19:15-19.

14. Davutoglu V, Kervancioglu S, Dinckal H, Soydinc S, Turkmen S, Akdemir I, et al. High incidence of occult femoral vein thrombosis related to multiple venous sheaths during electrophysiological studies. Heart 2004; 90:1061-2. doi: 10.1136/hrt.2003.027128.

15. Li L, Zhang BJ, Zhang BK, Ma J, Liu XZ, Jiang SB. Prevention and treatment of lower limb deep vein thrombosis after radiofrequency catheter ablation: Results of a prospective active controlled study. Sci Rep 2016; 6:28439. doi: 10.1038/ srep28439. 